\title{
COMPARING THE CONTENT OF MEdiCAL TOURISM FACILITATOR WEBSiteS IN IRAN AND OTHER COUNTRIES: A CORRESPONDENCE ANALYSIS
}

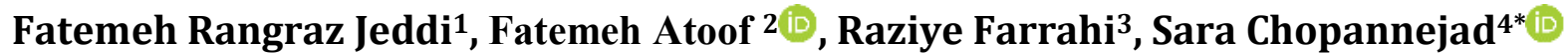

${ }^{1}$ Health Information Management Research Center, Kashan University of Medical Sciences, Kashan. Iran.

2Department of Biostatistics and Epidemiology, School of Public Health, Kashan University of Medical Sciences, Kashan, Iran.

${ }^{3}$ PhD Student, Health Information Management Research Center, Kashan University of Medical Sciences, Kashan, Iran.

${ }^{4}$ PhD Student, Department of Health Information Management, School of Health Management and Information Sciences, Iran University of Medical Sciences, Tehran, Iran.

\begin{tabular}{ll}
\hline Article Info & A B S T R A C T \\
\hline $\begin{array}{l}\text { Article type: } \\
\text { Research }\end{array}$ & $\begin{array}{l}\text { Introduction: } \\
\text { Mrticle History: }\end{array}$ \\
$\begin{array}{l}\text { Received: } 2019-06-10 \\
\text { Revised: } 2019-07-14\end{array}$ & responsibilities of this industry are mostly undertaken by agencies and \\
Accepted: $2019-09-20$ & facilitators acting as intermediaries between patients and service \\
& providers. As a key factor, websites provide extensive services to patients \\
& for a better presence in medical tourism market. The present study aimed \\
* to compare medical tourism websites and facilitators in Iran and other
\end{tabular}

* Corresponding author:

Sara Chopannejad

Phd Student, Department of Health

Information Management, School of

Health Management and

Information Sciences, Iran University

of Medical Sciences, Tehran, Iran.

email: sarachopannejad@gmail.com

\section{Material and Methods:}

Websites were selected based on the specified criteria such as content of websites which were examined using content analysis technique. The data belonging to website content were classified into two groups including medical and tourism services and information and communication issues. Correspondence analysis was done using two $\mathrm{R}$ packages (FactoMineR for analysis and fact extra for data visualization).

Results:

Of 42 selected websites, 19 was belonged to Iran, 11 to North America, 7 to South and Central America, and 5 to Asia. Medical tourism facilitators in North America and Asia tend to provide modern contact and legal information. Against Iranians' facilitators tend to show traditional contact and general information. South American websites provide more information about hospital accreditation. Iranian websites emphasized tourism-related information. Whereas, North American's are emphasized on cost-comparison lists.

\section{Conclusion:}

Results of the present study provide a snapshot of status of data provided on websites in terms of medical, tourist and communication services available in the studied websites and clearly showed that Iranian medical tourism facilitator websites act differently from those of other countries. Websites play important roles for guiding customers to make decisions regarding the medical journey. Therefore, Iranian medical tourism facilitator websites must reduce their differences with those of other countries in order to be more actively participate and earn more profit in this competitive market

Keywords:

Correspondence Analysis, Data Visualization, Medical Tourism, Facilitator Websites

How to cite this paper

Rangraz Jeddi F, Atoof F, Farrahi R, Chopannejad S. Comparing the Content of Medical Tourism Facilitator Websites in Iran and Other Countries: A Correspondence Analysis. Front Health Inform. 2019; 8(1): e21. DOI: 10.30699/fhi.v8i1.188

\section{INTRODUCTION}

Health tourism is a growing phenomenon of the 21st century, involving the domains of health, medicine, and wellness [ $[\underline{-2}]$. Of these domains, medical tourism is more important as it responds to the needs of patients [ $\underline{3}-\underline{4}]$. Medical tourism is defined as 
an organized journey of patients from their place of residence to somewhere else in order to receive appropriate health-related services []ㅡ, often focused on non-emergency services []ㅡ. The medical tourism market has received considerable attention as a growing, profitable industry with low costs, starting competition among countries [무요. An increasing trend is predicted for this industry in the following 10 years [9] , indicating that patients are ready to travel in order to receive high-quality, inexpensive services in a short time, especially services that they do not have access to or have to wait a long time for in their place of residence [ $\underline{10}$, $11]$. Iran is a country of four seasons, with numerous historical, religious, natural, and cultural attractions, in addition to modern and equipped healthcare centers, specialized human sources, and low-cost and high-quality health services. A large number of regional applicants and Iranian diaspora are willing to be treated in Iran. With regard to application terms and competitive advantages, Iran has a relatively good status and can participate in global markets while meeting regional healthcare needs [12].

\section{Role of Medical Tourism Facilitation Organizations}

The responsibilities of the medical tourism industry are mostly undertaken by agencies and medical tourism facilitators acting as intermediaries between patients and service providers [13, 14]. These facilitator agencies may even be located outside the target country. Nevertheless, they all aim to increase access to medical tourism services worldwide [15]. The primary contact between such organizations and patients takes place using information and communication systems, such as social media and website. Websites facilitate the selection of an appropriate medical tourism target by providing accurate information $[\underline{12}, \underline{16}]$.

\section{Role of websites in Medical Tourism Facilitator Organizations}

Medical tourism websites present information on treatment possibilities, explain the benefits of medical travel, affordability, short waiting time, high quality of services, and incorporated technologies [17]. This information facilitates patients' decisionmaking regarding the use of medical tourism services and the growth of medical tourism [18-20]. As a key factor in medical tourism and the most effective interactive tool, websites provide extensive services to patients and enhance the agency's marketing efforts for a better presence in the healthcare market [21-22]. Therefore, it is vital to pay attention to content of websites in order to promote this industry [23] . To facilitate medical tourism, the Iranian Ministry of Health and Medical Education has approved regulations for healthcare centers which provide services for medical tourists. These regulations necessitate the availability of a website with appropriate content in order to introduce the capabilities of centers, medical service marketing, and resolution of challenges [24], so this content would meet the needs of patients and provide a quick and comprehensive access to information $[\underline{25}, \underline{26}]$. However, few studies have so far examined the content of medical tourism websites, all descriptive in nature. Only one study conducted by Cormany et al. has employed correspondence analysis to compare the websites of medical facilitators [25]. The present study compared the content of websites of medical tourism facilitators in Iran and other countries using correspondence analysis considering the time of study, dynamic nature of the Internet, and high speed of changes in website content.

\section{Literature review}

Medical tourists seek access to services with low costs, high qualities, and different from those available in their place of residence [27]. They can access information required for decision-making regarding their medical journey on the Internet [28, 29]. Different studies conducted in the past decade on medical tourism have emphasized the important role of accessing information and interaction through medical tourism websites for the development of this industry [30, 31] , because applicants obtain information through websites as the first contact point of medical tourism [32]. The role of website content goes beyond the provision of information regarding facilities and tourist attractions. The content of websites forms a sense of trust in tourists in order to ensure that their safety and health are taken into account and they can start their journey to healthcare centers [33]. Cormany et al. evaluated 57 websites in North America, Asia, Europe, Central America, South America, and Africa. Results were classified based on two criteria: web page feature and services noted on the web page. Results revealed that in central Europe and South America, websites mostly focus on personal information, while agencies in North America prepared general information. Regarding services, North American websites emphasize on availability of services such as transferring medical records, payment services, and air transport, while European websites focus on planning of details such as medical appointments [25]. Frederick et al. examined the differences among websites of various regions. Results showed that there are differences among websites providing medical tourism services between Eastern and Western countries including cultural differences, prioritization for communication, and costs of specific services. It was also revealed that, contrary to Western websites, Eastern websites prefer to show patient testimonials 
[34]. In another study Abouhashem Abadi et al. classified medical tourism information and services in three levels and five categories based on the priority of representing services and information. Accordingly, based on similarities in content, services, and information. Results of studies on the content of top medical tourism websites have shown that the introduction of medical options is the most important type of content, followed by the introduction of facilities provided on websites, medical tourism, and patients' comments [35]. According to Lee et al. medical tourism websites often try to provide advantages and benefits of medical tourism and understate its risks. They also showed that availability of websites demonstrate the tendency of agencies for using social media in order to develop medical tourism [흐].

\section{MATERIAL AND METHODS}

\section{Search strategy}

Websites of hospitals and medical tourism facilitators in Iran were selected using nonsystematic sampling. Websites were identified using Google search engine with a combination of multiple keywords. The search strategy for retrieving Iranian medical tourism facilitator websites is depicted in Fig 1. In line with previous studies, the first three pages were examined [17].

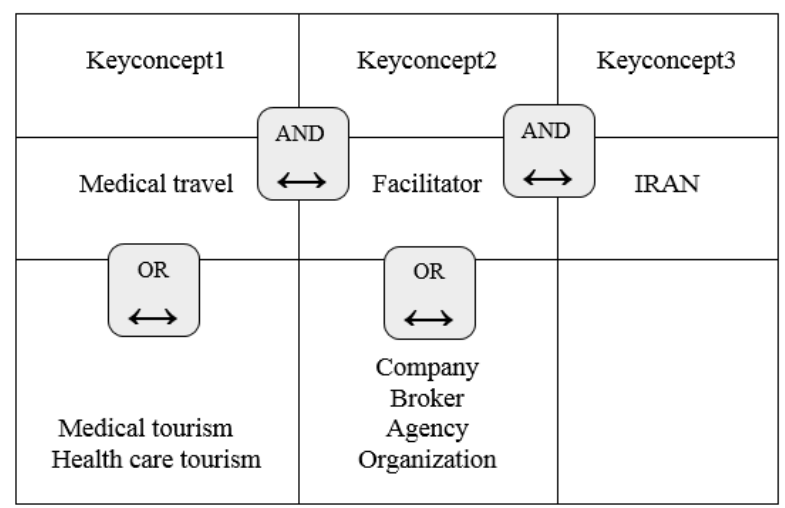

Fig 1: The search strategy for retrieving medical tourism facilitator websites

Purposive sampling was used to select the websites of other countries. To this end, the page of Member from Association section of Medical Tourism Association website was checked and a list of websites for hospitals and medical tourism facilitators created. All websites were checked in June 2017 due to the high speed of changes in website content (Appendix 1).

\section{Inclusion criteria}

In the present study, websites were defined as a collection of pages or files linked together which available on the Internet [ㅁ5]. Websites were selected based on the following criteria:

A) English version of the website should be available;

B) The major aim of the website should be medical tourism services.

C) The last update of websites should be in 2017 .

\section{Examining the content of websites}

Website content was examined using content analysis techniques. Websites were examined while making no judgment on their usability, structure, or design layout, and their content was investigated using a checklist resulted from previous study [37]. Which measured on a nominal "Present/Not Present" scale. The data belonging to website content were classified into two groups. The data related to customer relationship were classified under "Information and Communication", including:

- Postal address

- Phone number

- Information Request Form

- $\quad$ E-mail address

- Facebook

- Twitter

- Linkdin

- $\mathrm{G}+$

- U-tube

- Telegram

- Instagram

- Address, telephone number and email of hospitals

- Address, telephone number and email of hotels

- About us

- Accreditation organization

- Hospitals accreditation

- Action plan

- Legal-Privacy and confidentiality of information.

- Term and condition

- Disclaimer

- FAQ

- Service Satisfaction Questionnaire

The data related to medical and tourism services of organizations were classified under "Medical and 
Tourism Services", including:

1. Travel companies

2. Accommodation services-hotel list

3. Translation service

4. Destination and its culture

5. Pictures of tourist attraction

6. Introduction of medical service

7. Photos of medical service

8. Risks and treatment complications

9. Length of stay

10. Cost comparison list

11. Payment Services-Select International Insurance

12. Payment Services-Financing

13. Transfer of medical records

14. Hospitals List

15. Follow-up services

16. Make appointment

17. List of Physicians

18. Physicians Photos and bio

\section{Data analyzing method}

Correspond Analysis (CA) has been conducted since there were high volume and variety of information on the investigated websites. CA is an extension of principal component suited to explore relationships between qualitative or categorical variables. This method is used for summarizing and visualizing data set like principal component analysis. In a small twoway contingency table (formed by two categorical variable), Chi-square test could be used for evaluating of significant dependence between row and column categories, but when the data contains many categories, correspondence analysis is very useful to visualize the similarity between items.

The aim of CA is to have a global view of the data for useful interpretation. For a two-way contingency table, a common question is whether certain elements of row variable are associated with some elements of the column variable. Like principal component, eigenvalues can be used to determine the number of dimensions to retain. Dimensions are ordered decreasingly according to the amount of variance explained in the solution. A good dimension reduction is achieved when the first few dimensions account for a large proportion of the variability. Also this method of analysis provides factor scores for both row and column points of contingency table to visualize graphically the association between row and column elements in the contingency table in a low-dimensional space [38]. Correspondence analysis was done using two $R$ packages: i) FactoMineR for the analysis and ii) fact extra for data visualization.

\section{RESULTS}

Of 42 selected websites, 19 belonged to Iran, 11 to North America, 7 to South and Central America, and 5 to Asia (India, Turkey, South Korea, Thailand). Based on method of search, the most websites were in the north and South America and Asia. No websites from Africa, Europe, and Australia were investigated, because the search was done based on the Medical Tourism Association.

\section{Comparison of information related to contact with customers in the examined websites}

Evaluation of information and communications web pages (Fig 2) showed that dimension 1 explains $57.74 \%$ of variance, followed by dimension 2 (31.1\%), which totally explained $88.84 \%$ of variance that is an acceptable percentage. The contribution of third dimension was $11.15 \%$ that was lower than advised level of $20 \%$ for additional dimensions [39].

The quality numbers for four regions under review are: (C1) IRAN, 1; (C2) North America, 0.99; (C3) Central and South America, 0.99; (C4) Asia, 0.998. The quality number for each point is similar in its interpretation to the communality for a variable in factor analysis. The higher quality number (from 0 to 1 ), showed the better representation of the data [40]. The examination of themes belonging to the two axes suggested that Axis 1 has generally aligned website content according to contact information based on traditional methods (such as postal address) and modern communication information (such as social media).

Axis 2 may be aligned based on generalized information (About Us) and legal information (privacy). Accordingly, medical tourism facilitators in North America and Asia tend to provide modern contact and legal information on their websites. However, Iranian medical tourism facilitators tend to show traditional contact information and general information related to organizations. Contents around the intersection of the axes were those mentioned in the majority of medical tourism facilitator websites of different regions. Nevertheless, it is evident that Iranian websites differed from those of other regions and emphasized information regarding the patients' action plan. 


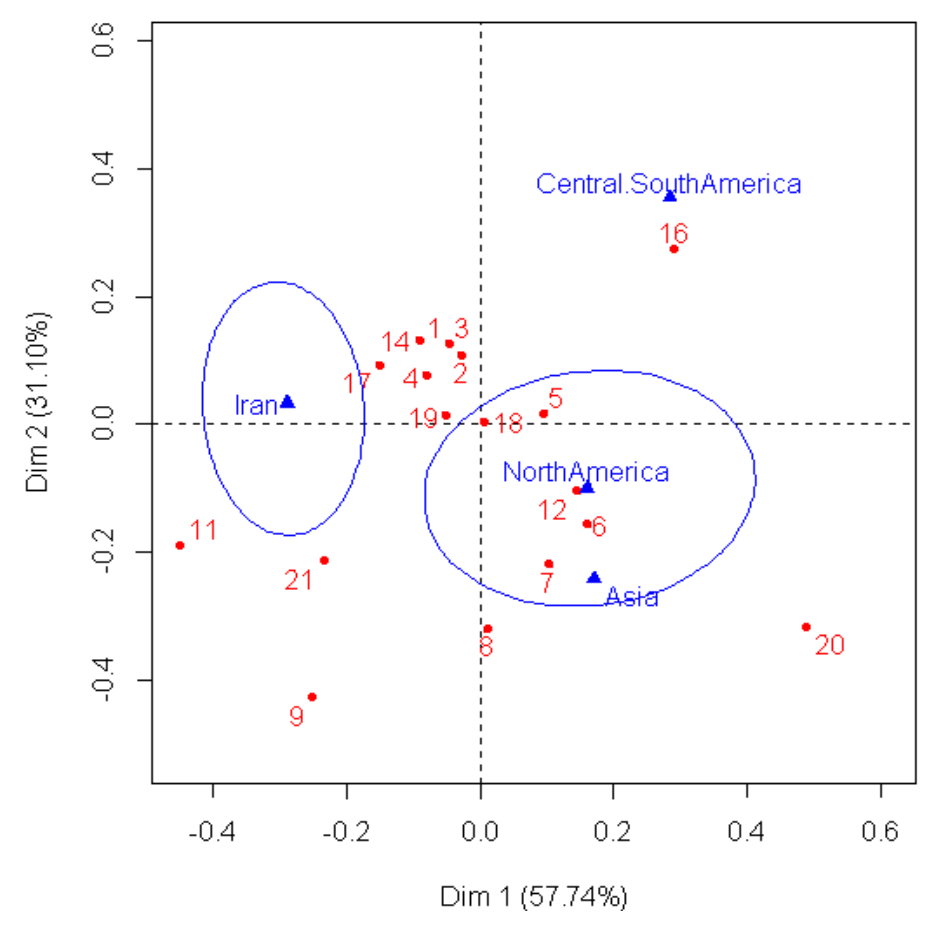

1. Postal address
2. Phone number
3. Information Request Form
4. E-mail address
5. Facebook
6. Twitter
7. linkdin
8. G+
9. U-tube
10.Telegram
11.Instagram

12. Address, telephone number and email of hospitals 13. Address, telephone number and email of hotels

14. A bout us

15. Accreditation organization 16. Hospitals accreditation 17. Action plan 18. Legal-Privacy and confidentiality of information. 19. Term and condition 20. Disclaimer

21. FAQ

22. Service Satisfaction Questionnaire

\begin{tabular}{|c|c|c|c|}
\hline Axis of web Contents & eigenvalue & percentage of variance & cumulative percentage of variance \\
\hline $\operatorname{dim} 1$ & 0.05731103 & 57.74495 & 57.74495 \\
\hline $\operatorname{dim} 2$ & 0.03086806 & 31.10177 & 88.84672 \\
\hline $\operatorname{dim} 3$ & 0.01106947 & 11.15328 & 100.00000 \\
\hline
\end{tabular}

Fig 2: Information and communication analysis

The availability of general information regarding the target hospitals and legal concepts of privacy and confidentiality was mostly aligned with North America and Asia. Moreover, websites belonging to these regions mostly tended to use professional communication networks such as linkedin, twitter, and facebook. Integral and telegram communication networks were closer to the Iranian axis, showing the tendency of people in this area to use the noted networks. Other measured features of different regions were so close to another and the intersection of axes that it was not possible to classify or differentiate them further.

Information such as postal address, phone number, email address, information request form, and about us was used on the websites of different regions. North American websites emphasized legal information regarding the privacy and confidentiality of patient information significantly more than other regions. Against, central and South American websites tended to provide information of hospital accreditation more than raising awareness in patients regarding their legal rights.

\section{CONTENT ANALYSIS OF MEDICAL AND TOURISM SERVICES PROVIDED TO CUSTOMERS}

Evaluation of medical and tourism service (Fig 3) showed that dimension 1 explains $62.55 \%$ of variance, followed by $22.46 \%$ of variance for 
dimension 2, which totally explained $84.57 \%$ of variance that is an acceptable percentage. The contribution of third dimension was $11.15 \%$ that was lower than advised level of $20 \%$ [39].

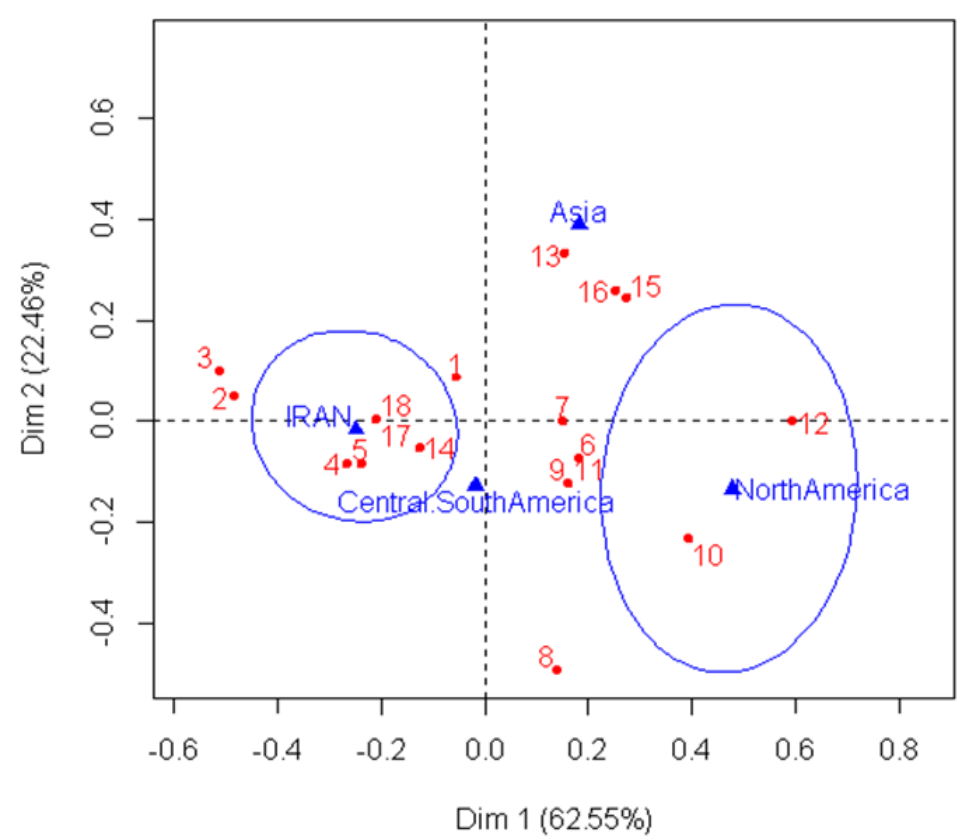

10. Cost comparison list

11. Payment Services-Select International Insurance

12. Payment Services-Financing

13. Transfer of medical records

14. Hospitals List

15. Follow-up services

16. Make appointment

17. list of Physicians

18. Physicians Photos and bio

\begin{tabular}{|c|c|c|c|}
\hline Axis of web Contents & eigenvalue & percentage of variance & cumulative percentage of variance \\
\hline 1 & $\operatorname{dim} 10.07875750$ & 62.55190 & 62.55190 \\
\hline 2 & $\operatorname{dim} 20.02828362$ & 22.46382 & 85.01572 \\
\hline 3 & $\operatorname{dim} 30.01886632$ & 14.98428 & 100.00000 \\
\hline
\end{tabular}

Fig 3: Medical and tourism service

The quality numbers for four regions under review are: (c1) Iran, 0.999; (c2) North America, 0.99; (c3) central and south America, 0.98; (c4) Asia, 1. The quality number for each point is similar in its interpretation to the communality for a variable in factor analysis. The higher quality number (from 0 to 1), showed the better representation of the results of the data [40].

Results showed that the difference between Iran and North America was larger than other regions. examination of themes belonging to two axes showed that axis 1 was aligned from the left (discussing tourist services introduced on websites) to right (focusing on medical services provided by medical tourism facilitators).
Axis 2 was aligned based on measures taken by patients to receive services in the medical tourism destination on one side, and on the highly important details which affected patients' decision regarding the medical journey on the other end.

Results also indicated that Iranian websites clearly emphasized tourism-related information by introducing the destination and its culture and discussing the features and facilities of accommodation services (hotel list). They also tended to introduce physicians, specialists, and hospitals that provided medical services. In addition, as Persian is the official language of Iran, translation services, especially for English, on the websites of this region are among services positioned near the 
cluster belonging to Iran.

Cost-comparison lists of payment services and financing were mostly emphasized in the North American cluster. Cost-comparison lists of payment services and financing were mostly emphasized in the North American cluster. North American tend to be advocating for travel out of the country for services, while most others are attempting to draw travelers to their country. That may explain the emphasis on legal and cost by the North American sites. Asian websites were located near services which must be done directly by the customer before starting the medical journey in order to ensure the availability of services in an appropriate time and place. These included services such as making appointment, reserving medical services, and transferring medical records. Furthermore, information regarding support and follow-up services after the medical journey was located near this region. Other measured features of different regions were so close to another's and the intersection of axes that it was not possible to classify or differentiate them further. In fact, some information related to medical services such as introduction of medical services, length of stay, and international insurance was equally emphasized by all regions. Still, the highly important feature of "risks and treatment complications" was placed significantly far from all clusters. This demonstrates the very little attention paid by all regions to this important issue. In the present study, the South American region did not emphasize any prominent service. However, the tendency of this region towards the Iranian cluster demonstrates the similarities between the websites of these two regions.

\section{DICUSSION}

The present study aimed to examine the information content provided to medical tourists through websites of medical tourism facilitators in Iran, Asia, and North, Central, and South America. Websites of active medical tourism facilitators which could be accessed through the Medical Tourism Association Database as well as websites belonging to medical tourism facilitator organizations in Iran were examined. Results of the present study provide a snapshot of the status of data provided on websites in terms of medical and tourist services and communication services available in the studied websites. The present study focused on the presence or absence of services, and does not ensure the quality of websites, accuracy of information, or violation of framing theory. Nevertheless, results of website content analysis clearly showed that Iranian medical tourism facilitator websites act differently from those of other countries. Iranian medical tourism facilitators mostly prefer to show traditional contact information and provide generalized information of their organization, with a special attention paid to details of patients' action plan. Information regarding tourist destinations and their culture and features and facilities of hotels was more available on Iranian websites than the websites of other regions. However, legal concepts and principles of privacy and confidentiality of information were under-represented in Iranian websites. The websites of other regions provided more information on privacy and confidentiality of information, especially regarding the nonresponsibility regarding the outcomes of medical journey.

Accordingly, medical tourism facilitators in North America and Asia tend to provide modern contact and legal information on their websites and agencies in Central and South American mostly focused on traditional contact information and legal information on the websites. But Cormany et al, said that in central Europe and South America, websites mostly focus on personal information, while agencies in North America show generalized information [25]. The present study resulted that Cost-comparison lists of payment services and financing were mostly emphasized in the North American and The South American region did not emphasize any prominent service. Also Cormany et al, said that North American websites emphasize the availability of services such as transferring medical records, payment services, and air transport, while European websites focus on the planning of details such as medical appointments [25].The importance of this study lies in that, not only the quality of services and costs, but also the country and organization providing the services, facilitator organization, and the websites play important roles as the key tool for guiding customers to make decisions regarding the medical journey.

\section{CONCLUSION}

By comparing the websites of medical tourism facilitators in Iran and other regions, prominent differences were found. Iranian medical tourism websites provided the information of hospitals in the destination with more details. For example, the list of hospitals, follow-up services, appointments, doctors lists, doctors photos and biographies were been on most Iranian websites. In other hand Iranian medical tourism websites further emphasized legal concepts and principles of privacy and confidentiality. As well as, most commonly used official communication media were Twitter, Facebook, and LinkedIn which were absent in other regions. Therefore, Iranian medical tourism facilitator websites must reduce their differences with those of other countries in order to more 
actively participate and earn more profit in this competitive market. We hope that the results presented here can provide a solution for improving the performance of websites, thus positively affecting the growing industry of medical tourism.

\section{AUTHOR'S CONTRIBUTION}

All the authors approved the final version of the manuscript.

\section{CONFLICTS OF INTEREST}

The authors declare no conflicts of interest regarding the publication of this study.

\section{FINANCIAL DISCLOSURE}

No financial interests related to the material of this manuscript have been declared.

\section{REFERENCES}

1. de la Hoz-Correa A, Muñoz-Leiva F, Bakucz M. Past themes and future trends in medical tourism research: A co-word analysis. Tourism Management. 2018; 65: 200-11.

2. Ebrahimzadeh I, Sakhavar N, Taghizadeh ZA. Comparative study of health tourism potentials in Iran and India. Journal of Subcontinent Researches. 2013; 5(15). 51-78.

3. Lunt N, Carrera P. Advice for prospective medical tourists: Systematic review of consumer sites. Tourism Review. 2011; 66(1/2): 57-67.

4. Jeddi FR, Arabfard M, Arabkermany Z, Gilasi H. The diagnostic value of skin disease diagnosis expert system. Acta Inform Med. 2016; 24(1): 30-3. PMID: 27046943 DOI: $10.5455 /$ aim.2016.24.30-33 [PubMed]

5. Carrera PM, Bridges JF. Health and medical tourism: what they mean and imply for health care systems [Internet]. 2006 [cited: 1 Mar 2019]. Available from: http://bit.ly/1dka0iT.

6. Crooks VA, Snyder J. Regulating medical tourism. The Lancet. 2010; 376: 1465-6.

7. Ayoubian A, Tourani S, Hashemi Dehaghi Z. Medical tourism attraction of Tehran hospitals. International Journal of Travel Medicine and Global Health. 2013; 1(2): 95-8.

8. Herrick DM. Medical tourism: Global competition in health care. National Center for Policy Analysis (NCPA). 2007; 304: 19-20.

9. Ganguli S, Ebrahim AH. A qualitative analysis of Singapore's medical tourism competitiveness. Tourism Management Perspectives. 2017; 21: 74-84.

10. Park J, Ahn J, Yoo WS. The effects of price and health consciousness and satisfaction on the medical tourism experience. J Healthc Manag. 2017; 62(6): 405-17. PMID: 29135765 DOI: 10.1097/JHM-D-1600016 [PubMed]
11. Adams K, Snyder J, Crooks VA, Johnston R. Promoting social responsibility amongst health care users: Medical tourists' perspectives on an information sheet regarding ethical concerns in medical tourism. Philos Ethics Humanit Med. 2013; 8: 19-29. PMID: 24314027 DOI: 10.1186/1747-5341-8-19 [PubMed]

12. Mahdavi Y, Mardani S, Hashemidehaghi Z, Mardani N. The factors in development of health tourism in Iran. International Journal of Travel Medicine and Global Health. 2013; 1(4): 113-8.

13. Gan LL, Frederick JR. Medical tourism facilitators: Patterns of service differentiation. Journal of Vacation Marketing. 2011; 17(3): 165-83.

14. Snyder J, Crooks VA, Adams K, Kingsbury P, Johnston R. The 'patient's physician one-step removed': The evolving roles of medical tourism facilitators. J Med Ethics. 2011; 37(9): 530-4. PMID: 21478420 DOI: 10.1136/jme.2011.042374 [PubMed]

15. Mohamad WN, Omar A, Haron MS. The moderating effect of medical travel facilitators in medical tourism. Procedia-Social and Behavioral Sciences. 2012; 65: 358-63.

16. Lunt N, Smith RD, Mannion R, Green ST, Exworthy M, Hanefeld J, et al. Implications for the NHS of inward and outward medical tourism: A policy and economic analysis using literature review and mixed-methods approaches. Health Services and Delivery Research. 2014. PMID: 25642508 [PubMed]

17. Maguire Á, Bussmann S, zu Köcker CM, Verra SE, Giurgi LA, Ruggeri K. Raising concern about the information provided on medical travel agency websites: A place for policy. Health Policy and Technology. 2016; 5(4): 414-22.

18. Hanefeld J, Lunt N, Smith R, Horsfall D. Why do medical tourists travel to where they do? The role of networks in determining medical travel. Social Science \& Medicine. 2015; 124: 356-63.

19. Farzandipur M, Rangraz Jeddi F, Azimi E. Factors affecting successful implementation of hospital information systems. Acta Inform Med. 2016; 24(1): 51-5. PMID: 27041811 DOI: 10.5455/aim.2016.24.51-55 [PubMed]

20. Yousra H, Baret I. Understanding the role of Internet in explaining the medical-tourist behavior: A conceptual model. Management \& Avenir Santé. 2015; 1(2):51-9.

21. Krasnoff PL. The survey says: Analysis of New York area hospital web sites. Healthcare Informatics. 2011; 18(10): 55-9.

22. Sarantopoulos I, Vicky K, Geitona M. A supply side investigation of medical tourism and ICT use in Greece. Procedia-Social and Behavioral Sciences. 2014; 148: 370-7.

23. Menvielle L, Menvielle W, Tournois N. Medical tourism: A decision model in a service context. Turizam. 2011; 59(1): 47-61.

24. The terms and conditions of medical centers of health tourists [Internet]. 2009 [cited: 15 Apr 2015]. Available

from: 
http://www.mums.ac.ir/shares/darman/DarmanSP-chapter47.pdf

25. Cormany D, Baloglu S. Medical travel facilitator websites: An exploratory study of web page contents and services offered to the prospective medical tourist. Tourism management. 2011; 32(4): 709-16.

26. Jeddi FR, Rezaiimofrad MR. Development of common data elements to provide tele self-care management. Acta Inform Med. 2013; 21(4): 241-5. PMID: 24554797 DOI: $10.5455 /$ aim.2013.21.241-245 [PubMed]

27. Hanefeld J, Lunt N, Smith R, Horsfall D. Why do medical tourists travel to where they do? The role of networks in determining medical travel. Soc Sci Med. 2015; 124: 356-63. PMID: 24976006 DOI: 10.1016/j.socscimed.2014.05.016 [PubMed]

28. Johnston K, Puczkó L, Smith M, Ellis S. Wellness tourism and medical tourism: Where do spas fit? Research Report: Global Spa Summit; 2011.

29. Mohseni S, Jayashree S, Rezaei S, Kasim A, Okumus F. Attracting tourists to travel companies' websites: the structural relationship between website brand, personal value, shopping experience, perceived risk and purchase intention. Current Issues in Tourism. 2018; 21(6): 616-45.

30. Seow AN, Choong YO, Moorthy K, Chan LM. Intention to visit Malaysia for medical tourism using the antecedents of theory of planned behaviour: A predictive model. International Journal of Tourism Research. 2017; 19(3): 383-93.

31. Samadbeik M, Asadi H, Mohseni M, Takbiri A, Moosavi A, Garavand A. Designing a medical tourism website: A qualitative study. Iran J Public Health. 2017; 46(2): 249-257. PMID: 28451562 [PubMed]

32. Sarantopoulos I, Vicky K, Geitona M. A supply side investigation of medical tourism and ICT use in Greece. Procedia-Social and Behavioral Sciences. 2014; 148: 370-7.

33. Smith M, Amorim E. Tourism, safety, and health information provided on European country websites: A content analysis. Revista Turismo \& Desenvolvimento. 2018; 1(27/28): 679-90.

34. Frederick JR, Gan LL. East-west differences among medical tourism facilitators' websites. Journal of Destination Marketing \& Management. 2015; 4(2): 98-109.

35. Abouhashem Abadi F. The components and contents of medical tourism facilitator websites. Journal of Tourism Management Studies. 2016; 11(33): 1-18.

36. Lee $\mathrm{H}$, Wright $\mathrm{KB}$, O'Connor $\mathrm{M}$, Wombacher $\mathrm{K}$. Framing medical tourism: An analysis of persuasive appeals, risks and benefits, and new media features of medical tourism broker websites. Health Commun. 2014; 29(7): 637-45. PMID: 24138286 DOI: 10.1080/10410236.2013.794412 [PubMed]

37. Jeddi FR, Chopannejad S. A systematic review of the content of medical tourism websites and their evaluative criteria. Research Journal of Pharmaceutical, Biological and Chemical Sciences.
2017; 8(2): 1440-52.

38. Mason AM, Wright KB, Bogard J. Assessing cultural representations of physician and patient imagery in medical tourism websites. Journal of Intercultural Communication. 2011; 25: 1-5.

39. Clausen S. Applied correspondence analysis. Thousand Oaks, CA: Sage Publications; 1998.

40. Hair JF, Black WC, Babin BJ, Anderson RE, Tatham RL. Multivariate data analysis (6th Ed.). Upper Saddle River, NJ: Pearson Prentice Hall; 2006. 